\title{
Vicissitudes de uma obra: o caso do Diário de Lúcio Cardoso
}

Cássia dos Santos Faculdades Integradas Metropolitanas de Campinas

\section{O lançamento do primeiro volume do Diário}

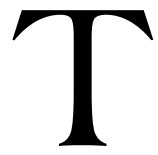

erça-feira, 31 de maio de 1960. A coluna "Vida Literária" de Mauritônio Meira, publicada no Caderno B do Jornal do Brasil, Cardoso. antecipava a notícia do aparecimento de um novo livro de Lúcio

Após um período de 16 anos em que não editara romance algum - o último deles, Dias perdidos, datava de 1943 -, o autor havia atraído a atenção dos leitores e da crítica no ano anterior com o lançamento da Crônica da casa assassinada. Tendo chegado às estantes das livrarias no mês de março, o livro havia alcançado uma pronta repercussão e, no curto intervalo de cinco meses - entre 4 de abril e 12 de setembro -, fora objeto de pelo menos 24 diferentes artigos nas revistas e suplementos literários do Rio de Janeiro e de São Paulo. ${ }^{1}$

Ainda que a singularidade do romance de 1959 no conjunto da obra do escritor pudesse justificar tais números, o que também contribuíra para eles fora uma polêmica desencadeada pelo crítico pernambucano Olívio Montenegro. Acusando Lúcio Cardoso de haver pretendido causar escândalo ao centrar o enredo da Crônica da casa assassinada em torno de um relacionamento incestuoso, Montenegro conseguira, com seu artigo "Um romance imoral", despertar o interesse de muitos pelo livro. Usando a situação a seu favor, o ficcionista respondeu aos ataques com uma espécie de depoimento, divulgado na coluna “Escritores e livros” de José Condé no

\footnotetext{
${ }^{1}$ Confira ao término de meu texto, após as Referências bibliográficas, a lista de textos organizada segundo a ordem cronológica de publicação.
} 
Correio da Manhã, ao qual se seguiram outros textos de vários autores, entre os quais uma enquete promovida por Walmir Ayala sobre a suposta imoralidade do romance.

Com o nome posto em relevo nos jornais, Lúcio finalmente encontrou condições favoráveis para concretizar um antigo projeto: a publicação de um diário íntimo, inspirado na leitura daqueles elaborados por André Gide e Julien Green, cujas obras admirava. A Organização Simões, por meio de seu selo Elos, seria a responsável pela edição do livro, que, a julgar pelo que se lê abaixo, não havia sido aceito pela José Olympio:

\section{VIDA LITERÁRIA}

Mauritônio Meira

Diários íntimos de Lúcio Cardoso serão publicados finalmente: pela Simões

Vão ser publicados, finalmente, os cinco volumes do Diário intimo do romancista Lúcio Cardoso. A edição do primeiro volume está sendo feita febrilmente pela Simões que, para isso, suspendeu todo seu trabalho editorial. Simões planejou o lançamento da primeira edição para julho, anunciando que guardará a composição do livro para uma segunda edição "que será necessária imediatamente", dado o grande interesse que o livro despertará.

A propósito, o romancista nos disse que "não se trata de um diário de literatura", mas, simplesmente do "diário íntimo de um escritor", escrito dia a dia.

O LIVRO E O AUTOR

Como se sabe, correm as seguintes informações nas rodas literárias sobre esse livro:

1 - É uma confissão aberta de cenas do dia-a-dia do escritor, incluindo até descrições de práticas de homossexualismo;

2 - É um livro que foi recusado por alguns editores, inclusive por José Olympio, lançador tradicional das obras de Lúcio Cardoso;

3 - Pessoas que tiveram acesso aos originais consideram-no um "livro forte demais para o Brasil".

A esse respeito, disse-nos Lúcio Cardoso:

- Não é bem isso. O livro não foi recusado por editores, como se diz. Levei-o ao editor Ênio Silveira, da Civilização, que, para publicá-lo, exigiu uma leitura prévia de um comitê de pessoas - que nomearia com o que não concordei. 


\section{VEM DESDE 49 ATÉ HOJE}

Os cinco volumes abrangem um período que vem de 1949 até hoje. O primeiro inclui os fatos ligados à vida de LC de 1949 a 1951. Todos serão publicados sob o título único de Diários, com a numeração alusiva a cada volume, com capa de Carlos Penafiel.

Referindo-se a seu livro, disse o escritor:

- Acho muito importante publicar esse livro, porque a literatura brasileira é pobre em "papéis íntimos". O autor brasileiro não se confessa. Meu livro é uma confissão. Não é um diário de literatura. É o diário da vida de um escritor. Evidentemente, como idéias fazem parte de minha vida, lá existem muitas. Mas não se trata de anotações de leituras. É a minha vida - e só. ${ }^{2}$

Se não há como saber se as informações veiculadas na coluna de Mauritônio Meira correspondem ou não de todo à verdade, nem por isso há motivo para que sejam desconsideradas. Revelando a curiosidade com que o Diário era aguardado no meio literário, Meira destacava a expectativa dos editores de que a obra, com lançamento previsto para julho, se esgotasse rapidamente. No mês de setembro, contudo, a impressão dos exemplares aparentemente ainda não havia sido encerrada, pois, em artigo publicado no dia 10 no Suplemento Dominical do Jornal do Brasil e intitulado "Diário: Lúcio Cardoso - a véspera do livro", Walmir Ayala afirmava que Simões prometera para o mês seguinte a finalização do processo.

É possível, no entanto, que apenas em novembro a edição da obra tenha sido de fato ultimada. No final desse mês, mais uma vez a coluna de Mauritônio Meira conferiria destaque ao romancista mineiro, dando-lhe a oportunidade de se pronunciar sobre o significado do novo livro. Entrevistado pelo jornalista e crítico Fausto Cunha, que respondia pela coluna naquele momento, Lúcio Cardoso definiu o Diário como um punhal erguido contra Minas Gerais:

\footnotetext{
${ }^{2}$ MEIRA, 31 maio 1960. Na reprodução desse fragmento de jornal, assim como na dos outros textos existentes nesse ensaio, atualizei, quando necessário, a ortografia de acordo com as normas vigentes. Tal procedimento não foi adotado em relação à grafia dos nomes próprios, contudo. Erros evidentes foram corrigidos na transcrição dos textos manuscritos e datiloscritos citados, embora tenha sido respeitada a pontuação originalmente utilizada por seus autores.
} 


\section{VIDA LITERÁRIA}

INTERINO

Lúcio Cardoso (patético): "Ergo meu livro como um punhal contra Minas"

O livro está sobre a mesa, negro como as paredes do inferno, com letras de fogo como as chamas do inferno. Ainda não o abrimos. Não se pode ler Lúcio Cardoso desprevenido. Na verdade, é difícil lê-lo imparcialmente. Ou somos contra, ou somos a favor. Não haverá, talvez, autor brasileiro mais afirmado e mais negado do que o romancista de $A$ luz no subsolo. Há quem o compare a Julien Green. Mas a que Julien Green? Também este é cambiante, é versicolor. No entanto, o Diário aí está e é preciso conversar com Lúcio Cardoso antes de mergulhar no seu mundo.

"A VERDADE TODA"

INT. - O que é o Diário, Lúcio, o que significa na sua vida literária, na sua vida?

LC - Perguntar-me o que significa o Diário é perguntar o que significa sua publicação, e, portanto, minha obra atual, começada com a Crônica da casa assassinada. Que me perdoe o tom pessoal, mas chega o momento em que a afirmação da verdade, da verdade TODA, é a única coisa possível, pelo menos se nos consideramos escritores.

MOVIMENTO DE INSUBMISSÃO

INT. - O Diário ...

LC - O Diário, como a Crônica, como O viajante, que será lançado dentro em breve pela Livraria José Olympio, tem para mim, pessoa humana e não escritor, o significado de um formidável movimento de luta e de insubmissão, contra esse elemento discordante, atroz e mesmo atentatório à grandeza de Deus que se chama a minha infância, sua permanência, pelo menos no que ela tem de mais ilegítimo e de mais poético.

"COMO UM PUNHAL"

Pretendíamos entrevistar o memorialista, mas vemos, que, em vez disso, estamos recebendo um documento humano, que precisamos registrar verbatim ac literatim. E não o interrompemos.

LC - "Meu movimento de luta, aquilo que busco destruir e incendiar pela visão de uma paisagem apocalíptica e sem remissão, é Minas Gerais. Meu inimigo é Minas Gerais. O punhal que levanto, com a aprovação ou não de quem quer que seja, é contra Minas Gerais. Que me entendam bem: contra a família mineira. Contra a literatura mineira. Contra a 
concepção de vida mineira. Contra a fábula mineira. Contra o espírito bancário que assola Minas Gerais. Enfim, contra Minas, na sua carne e no seu espírito. Ah, mas eu a terei escrava do que surpreendi na sua imensa miséria, no seu imenso orgulho, na sua imensa hipocrisia. Mas ela me terá, se for mais forte do que eu, e dirá que eu não sou um artista, nem tenho o direito de flagelá-la, e que nunca soube entendêla como todos esses outros - artistas! que afagam não o seu antagonismo, mas um dolente cantochão elaborado por homens acostumados a seguir a trilha do rebanho e do conformismo, do pudor literário e da vida parasitária. Ela me terá - se puder. Um de nós, pela graça de Deus, terá de subsistir. Mas acordado."

Levantamo-nos. E de repente nos vem à memória um verso de Housman: "I, strange and afraid/ In a world I never made". Mas o verso é esse mesmo? E de Housman??

Com essa entrevista, que, segundo Marcos Konder Reis, "no seu tempo, deu tanto o que falar", ${ }^{4}$ o autor, oscilando entre a veemência e o espalhafato, tornava patentes os conflitos que o afligiam. Esses não passaram e nem passariam despercebidos àqueles que lessem com cuidado o Diário, porém. Manuel Bandeira, um dos primeiros a se manifestar sobre a obra em artigo publicado em dezembro de 1960 , depois de explicar como se sentira incomodado, durante a leitura da Crônica da casa assassinada, com o estilo quase idêntico de todos os narradores, observava:

${ }^{3}$ CARDOSO, 25 nov. 1960. Sem reproduzir as questôes e os comentários feitos pelo entrevistador, o depoimento de Lúcio foi publicado, também, no número 2 da revista Fiç̧ão, em que foi erroneamente apresentado como texto inédito. Na versão divulgada pelo periódico, porém, as críticas do romancista a Minas são ainda mais abrangentes, como pode ser comprovado pela leitura do fragmento abaixo, em que figuram em negrito os trechos ausentes do pronunciamento veiculado pelo Jornal do Brasil:

"Meu inimigo é Minas Gerais.

O punhal que eu levanto, com a aprovação ou não de quem quer que seja é contra Minas Gerais.

Que me entendam bem: contra a família mineira. Contra a literatura mineira. Contra o jesuitismo mineiro. Contra a religião mineira. Contra a concepção de vida mineira. Contra a fábula mineira. Contra o espírito judaico e bancário que assola Minas Gerais. Enfim, contra Minas, na sua carne e no seu espírito.”

${ }^{4}$ REIS, 30 nov. 1968. 
Agora Lúcio inicia a publicação do seu "Diário". Aqui não haverá que fazer restriçôes desse gênero. Aqui temos Lúcio contando na sua própria voz o seu próprio romance. E as confidências de Lúcio interessam a gente, sacodem a gente por aquele mesmo misterioso toque de inquietação - a apreensão "do que pode acontecer". Vemos nestas páginas um homem em luta consigo mesmo, com o seu destino, com o seu Deus. E como esse homem é rico de sensibilidade, de inteligência, fundamentalmente nobre e bom e corajoso, o seu "Diário" empolga-nos desde as primeiras linhas e, terminado o volume, fica-se ansioso pela continuação prometida. No meu caso de amigo e admirador de Lúcio, faço votos para que o romance tenha um fim não do gosto do romancista para os romances que inventa - um "happy end". 5

Jorge Amado, por sua vez, em resenha publicada na revista Leitura, avaliando a importância do livro na carreira do escritor, chamava a atenção para o que de terrível existia nele, "esse livro dilacerante, esse coração exposto, esse sangue correndo, essa solidão do homem", ${ }^{6}$ que o haviam impressionado vivamente, como se verifica abaixo:

Passo a noite, até a madrugada, lendo o primeiro volume do "Diário", de Lúcio Cardoso (1949-1951). E quando termino a leitura e consigo dormir, o livro não me abandona, sonho com ele, vejo Lúcio desesperado na praia, às voltas com câmeras de cinema e com seu drama interior. Livro dramático e doloroso, livro terrível. Encontro Lúcio Cardoso, dias depois, numa livraria, em Copacabana, autografando seu livro. A livraria está cheia, é uma espécie de triunfo, de consagração do escritor. Lúcio, sentado ante a mesa, assinando, parece-me um pouco perdido entre tanta gente, tanto ruído, tantos abraços. Como um náufrago envolto numa tempestade. Demoro-me um pouco a espiá-lo, ele não sabe direito o que fazer, é a negação de tudo isso, desse ruidoso lançamento. Seu livro também, esse livro de alma despedaçada, de busca sem remédio, de homem afogando-se mas lutando contra as ondas. ${ }^{7}$

\footnotetext{
${ }^{5}$ BANDEIRA, 3 dez. 1960.

${ }^{6}$ AMADO, dez. 1960.

${ }^{7}$ AMADO, dez. 1960.
} 
Os dilemas e sofrimentos evidenciados por Lúcio em suas confissōes, no entanto, não parecem haver encontrado eco no espírito do grande público. Assim, a despeito do "ruidoso lançamento" testemunhado por Jorge Amado, da entrevista concedida a Fausto Cunha, que tantos comentários deve ter provocado naquele momento, e da expectativa dos editores de que o Diário tivesse uma ótima vendagem, o livro não conheceu outra edição em vida do autor. Embora tenha tido uma boa recepção crítica - também Alceu Amoroso Lima, Hildon Rocha, Octavio de Faria e Alcântara Silveira, entre outros, escreveram sobre ele -, seu conteúdo voltaria a ser publicado somente no ano de 1970, incorporado ao volume do Diário completo, de que se tratará em seguida.

\section{Os originais do Diário no Arquivo Lúcio Cardoso e a publicação do Diário completo}

No Arquivo-Museu de Literatura Brasileira da Fundação Casa de Rui Barbosa, depositária do Arquivo Lúcio Cardoso, acham-se reunidos e catalogados originais do romancista, sua correspondência, documentos pessoais e iconográficos, recortes de jornal sobre sua obra, entre outros. Entre os documentos de natureza diversa, existe um contrato de três folhas firmado por Maria Helena Cardoso e a editora José Olympio, representada por Daniel Joaquim Pereira e seu sobrinho Geraldo Jordão Pereira, para a publicação do Diário completo.

Em 7 de dezembro de 1962, Lúcio Cardoso sofrera um acidente vascular cerebral, que o tornara hemiplégico e comprometera gravemente sua capacidade de fala. Recuperado apenas parcialmente, passara a residir a partir de então com a irmã Maria Helena até sua morte em 24 de setembro de 1968, em decorrência de complicações causadas por um segundo derrame. Depois do lançamento do Diário I em 1960, ele não dera a lume mais nenhum livro e, a partir de 1963, impossibilitado de dar continuidade à sua obra literária, passara a se dedicar à pintura e ao desenho. Nesse mesmo ano de 1963, saíra a segunda edição da Crônica da casa assassinada, não mais pela José Olympio e, sim, pela Letras e Artes, e, em 1968, pouco antes da morte do ficcionista, a Editorial Bruguera pusera à venda, em formato de livro de bolso, a terceira edição do romance.

O primeiro volume do Diário apresentara as anotações de Lúcio referentes ao período de 14 de agosto de 1949 (dia em que completava 37 
anos) a 17 de março de 1951 . Haviam restado entre os seus papéis cadernos e textos datilografados com anotaçôes inéditas e datadas de março de 1951 a outubro de $1962 .{ }^{8}$

Após o falecimento do irmão, Maria Helena Cardoso, na qualidade de legatária dos direitos de sua obra, dedicou-se a procurar interessados em publicar um novo volume do Diário, que abarcasse a totalidade dos apontamentos existentes. Fechado o acordo com a José Olympio, foi assinado um contrato entre as duas partes, não-datado, que teve como testemunhas, entre outros, Rachel de Queiroz, Paulo Rónai e Luís Jardim. Nele estabelecia-se, entre outras cláusulas e condiçôes, que caberia à Maria Helena a entrega dos originais e que ficaria "a cargo exclusivo da EDITORA tudo que diz respeito ao aspecto material da OBRA, sua confecção, papel, formato, capa, feição gráfica, tiragem, preço, modo de venda e propaganda, e distribuição."

Com o esmero e o cuidado que eram peculiares ao trabalho realizado na Casa, a José Olympio preparou uma bela edição para o Diário completo em convênio com o Instituto Nacional do Livro, lançou um volume ilustrado, com várias fotos de Lúcio Cardoso, sozinho ou acompanhado de outras pessoas (sua mãe, irmãos, amigos ou escritores), e com fac-símiles de trechos de manuscritos e até de sua certidão de batismo. Trazia, ainda, uma "Nota" com os dados biobibliográficos do romancista, a reprodução de um poema de Carlos Drummond de Andrade a ele dedicado e a transcrição de pequenos fragmentos extraídos de textos críticos a seu respeito. A capa e contracapa haviam sido compostas tendo por base duas diferentes fotografias

\footnotetext{
${ }^{8}$ Em verdade, é importante esclarecer que também se encontra catalogado no Arquivo um outro conjunto de originais sob o título de Diário: formado de 150 folhas datilografadas no reto e com algumas correções manuscritas feitas a caneta pelo próprio Lúcio, esse material parece ter sido organizado por ele com vistas a uma possível publicação. Abrange o período de novembro de 1942 a novembro de 1947 e difere bastante do Diário aqui analisado por não possuir nenhum caráter confessional. É uma espécie de "diário de leituras" do autor, um registro das suas impressóes sobre romances, vários livros da Bíblia e sobre textos de Freud e Nietzsche.

${ }^{9}$ CONTRATO entre a Livraria José Olympio Editora S.A. e Maria Helena Cardoso para a publicação do Diário completo de LC. Rio de Janeiro, s.d. 3 fls. Disponível para consulta no Arquivo Lúcio Cardoso da Fundação Casa de Rui Barbosa.
} 
de Lúcio e o livro continha, por fim, uma relação com todos os seus títulos e na qual figurava, equivocadamente, o ano de 1961 como relativo à publicação do Diário I. ${ }^{10}$ Constituído de 306 páginas, além de 24 outras iniciais, parte delas numeradas em algarismos romanos, o Diário completo ficou assim dividido:

Diário I - 14 de agosto de 1949 a 17 de março de 1951 - p. 3-170;

Diário II - 12 de maio de 1952 a 17 de outubro de 1962 - p. 171-304.

Sendo obra de publicação póstuma, era de esperar que exibisse o nome do responsável pela sua organização. O dado, entretanto, foi omitido do volume, ao contrário do que se passou com todos os demais livros de Lúcio editados postumamente.

O romance $O$ viajante, lançado em 1973, pela José Olympio, e os Poemas inéditos, em 1982, pela Nova Fronteira, foram organizados por Octavio de Faria, que recolheu e ordenou todo o material neles existente, assinando ainda a "Introdução", que precede o texto do romance, e a "Nota editorial", que acompanha a coletânea de poemas. Devemos a André Seffrin e a Antonio Arnoni Prado, por sua vez, a organização das outras obras do escritor mineiro lançadas recentemente, que encerram originais até então parcialmente inéditos: Inácio, O enfeitiçado e Baltazar, em 2002, pela Civilização Brasileira, e o Teatro reunido, em 2006, pela Editora UFPR.

Não se sabe a quem coube a tarefa de ordenar e preparar os fragmentos do Diário para sua inserção no Diário completo. Mario Carelli assegura em Corcel de fogo que o livro teria sido editado "graças aos bons cuidados de Walmir Ayala." 11 As pesquisadoras Rosângela Florido Rangel e Eliane Vasconcellos Leitão, por seu turno, encarregadas da catalogação do Arquivo do autor na Fundação Casa de Rui Barbosa, informam no texto introdutório ao Inventário do arquivo Lúcio Cardoso que teria sido Octavio de Faria o responsável por tal missão. ${ }^{12}$

${ }^{10}$ Como, por um lapso, a editora Elos não fizera constar no Diário o ano de sua publicação, a José Olympio adotou 1961 na relação de títulos citada, erro que acabou se perpetuando em tantos estudos e ensaios.

${ }^{11}$ CARELLI, 1988, p. 112.

${ }^{12}$ FUNDAÇÃO CASA DE RUI BARBOSA, 1989, p. 14. 
Se não há como confirmar ou negar a participação de Walmir Ayala na preparação dos originais do Diário completo, é possível descartar, em contrapartida, a hipótese de que o criador da Tragédia burguesa tenha sido o seu organizador. Ao que tudo indica, Octavio teria se limitado a emitir algumas considerações sobre a seleção de trechos a serem incorporados no volume, como mostra uma carta por ele escrita e datada de 13 de abril de 1967.

Entre os originais do Diário que subsistiram no Arquivo, ${ }^{13}$ encontramse, além do conjunto de textos já citado na nota 8 , de folhas avulsas e de alguns cadernos de manuscritos dos quais ainda tratarei nesse ensaio, duas pastas com textos datilografados. A segunda dessas pastas que menciono é formada por cópias, na maioria duplas e feitas por meio de papel-carbono, de todas as folhas que constituem o material da primeira.

Essa guarda 145 folhas datilografadas no reto e numeradas e compreende, aparentemente, a primeira reunião dos fragmentos que iriam dar origem ao texto do Diário completo. Seu conteúdo deve ter sido totalmente copiado dos cadernos e dos eventuais datiloscritos que, até aquele momento, haviam restado do Diário de Lúcio, visto que, em meio a anotações inéditas, figuram uma série de outras que já haviam integrado o primeiro volume do Diário publicado em 1960.

O texto parece ter sido revisado por mais de um leitor. Correções de erros de datilografia, bem como de ortografia, acentuação, pontuação, concordância e regência, foram feitas, a lápis e a caneta, em todas suas folhas. À margem, foram assinalados também, através das indicações "repetição" e “já publicado", todos os segmentos que supostamente teriam sido incluídos no livro lançado anteriormente. Cabe ressaltar, por fim, que os números originalmente existentes nas primeiras 65 páginas foram rasurados e substituídos por outros, em tinta vermelha, respeitando-se apenas a partir da p. 66 a numeração que havia sido datilografada inicialmente.

No início de 1967, momento em que Lúcio Cardoso ainda estava vivo, esse material foi encaminhado a Octavio de Faria para que expressasse sua opinião a respeito. No mês de abril, Octavio o devolveria, acompanhado da carta aqui referida, na qual tecia comentários, recomendava supressões e apontava a necessidade de algum esclarecimento adicional nas passagens que

\footnotetext{
${ }^{13}$ LC 13 pi: DIÁRIO. Rio de Janeiro, 1957. 660 fls. + 241 fls. - cópia. Anexo: cadernosdiários e notas esparsas. Disponível para consulta no Arquivo Lúcio Cardoso.
} 
julgara obscuras. Fiel ao amigo de tantos anos, não hesitava em destacar a importância da obra, recomendando a sua pronta publicação:

Meu caro Lúcio,

Achei o seu "Diário", conforme Helena deve ter contado a você, ótimo, ainda mais interessante que o anterior. Urge publicá-lo. Lulu me disse que você gostaria que eu desse alguns "palpites". Aí vão, com toda sinceridade. Nem de outra forma eles teriam qualquer interesse para você.

Ao que me parece, o novo volume $\left(2^{\circ}\right)$ deve começar à pag. 39 do manuscrito datilografado (aliás, datilografado com bastantes falhas, principalmente nas 10 ou 12 páginas finais, onde há várias frases que ficaram quase sem sentido) no local em que se lê: "Maio 1951". A não ser que você queira editar uma espécie de "Diário Completo", repetindo (ainda que resumidamente) passagens do volume já publicado. (Este vai de agosto de 1949 a 17 de março de 1951.)

Seguem-se algumas observaçóes ligeiras, feitas ao sabor da leitura - e a confrontar com o texto original (Nada assinalei no texto datilografado, de modo que você possa "resolver", antes. $)^{14}$

Além de reforçar a idéia de que os apontamentos transcritos nessas folhas, fossem eles inéditos ou não, haviam sido reproduzidos dos originais do Diário, a carta de Octavio evidencia outros fatos. Observa-se, em primeiro lugar, que a decisão de editar o Diário completo deve ter sido tomada pelo próprio Lúcio, tendo Maria Helena Cardoso, após sua morte, dado prosseguimento a uma iniciativa sua. Diante das dúvidas expressas por Octavio de Faria sobre as marcas no texto, é possível concluir, também, que mais de uma pessoa teria proposto correções e opinado sobre a manutenção ou não de determinados fragmentos na versão datilografada:

p. 43 (fim) - A propósito da peça de Nélson Rodrigues. Quem fez as marcaçōes à tinta, e quem, a lápis? O que é que vale? É o sim (isto é, conserve-se) ou o não (exclua-se)? Eu opinaria pela exclusão. Inclusive porque, não havendo indicação do nome da peça, o "É claro,

\footnotetext{
${ }^{14}$ Carta de Octavio de Faria a Lúcio Cardoso. Teresópolis, 13 abr. 1967. 4 fls. Disponível para consulta no Arquivo Lúcio Cardoso. A Lulu mencionada acima chamava-se Heloísa de Faria, era irmã de Octavio e amiga de Maria Helena.
} 
execrável" atinge todo o teatro do Nélson. Teria sido essa sua real intenção? Nesse caso...

p. 46 - dia 15 - Várias vezes, no texto, aparecem comentários escritos a lápis com os dizeres: "repetição". Creio que são repetições, mais ou menos, de opiniões emitidas em volume já publicado. Não? Seria preciso, então, confrontá-las com as do dito volume. E decidir pela supressão, às vezes - Outras, não.

(...)

p. 97 - trecho riscado a lápis - Afinal, você resolveu que fique ou não?

Quem riscou? Quem escreveu "deve permanecer"? Pessoalmente, voto pelo "não permanecer"... ${ }^{15}$

Se interessa discutir quem teria participado da escolha e ordenação dos trechos compreendidos nessas folhas, quem teria se envolvido na publicação do Diário completo e, em última instância, a quem teria sido atribuída a responsabilidade principal de organizá-lo, isso ocorre devido às muitas falhas que o prejudicam.

A comparação dos manuscritos subsistentes do Diário, depositados no Arquivo do escritor, com o conteúdo da segunda parte do livro - aquela que abarca o período de maio de 1952 a outubro de 1962 - demonstra a existência de problemas de natureza variada. Há muitos fragmentos na obra cujas datas não correspondem àquelas presentes nos manuscritos; há apontamentos de dias diferentes, que, transformados em um único, ganharam uma terceira data; há, também, trechos que ainda permanecem inéditos, provavelmente por integrarem folhas avulsas e um caderno, que, na época da publicação do volume, estavam temporariamente desaparecidos.

Merece ainda ser sublinhado que parte das incorreçóes do Diário completo teve sua origem no material datilografado aqui em análise, o que me leva a acreditar que esse seja a sua primeira versão. Os fragmentos que constam das páginas 8, 9 e 10 (numeradas inicialmente como 30, 31 e 32), e que se referem a anotações do manuscrito datadas de 17 de agosto, 23 de setembro e 29 de outubro de 1951, repetem-se de forma um pouco modificada nas páginas 48, 49 e 54 (numeradas inicialmente como 50, 51 e 56). Quando o texto foi revisado, optou-se por não reproduzir justamente

${ }^{15}$ Carta de Octavio de Faria a Lúcio Cardoso. Teresópolis, 13 abr. 1967. 4 fls. 
os fragmentos das p. 48, 49 e 54, que traziam as datas corretas. À margem, lê-se a abreviação "rep.", que evidencia o que causou a exclusão.

Um apontamento sobre a Crônica da casa assassinada de 14 de novembro de 1955, integrante das folhas esparsas que subsistiram do Diário, foi equivocadamente somado a um trecho de um apontamento de 18 de outubro de 1954 já no texto datilografado, passando ambos a exibir aí, portanto, a mesma forma que juntos assumiriam no Diário completo, em que figuram como sendo do dia 14 de janeiro de 1953. Quase todas as anotações que, na obra, referem-se a esse ano, o de 1953, também já aparecem nas folhas datilografadas juntas e na mesma seqüência em que seriam editadas posteriormente, muito embora sejam, de fato, de anos distintos. Um dos cinco fragmentos que datam de 13 de novembro de 1955 também foi apresentado como sendo de 17 de outubro de 1960 já nessa versão.

O cotejo entre os cadernos manuscritos, as folhas datilografadas e o livro revela, também, que erros de transcrição cometidos nas folhas foram incorporados ao texto publicado. É o caso, por exemplo, de um trecho relativo ao dia 24 de junho de 1957 :

Amar, a cada momento me parece mais difícil. Sondo a mim mesmo com inquietação, perguntando se não é a possibilidade do amor que morreu em minha natureza. Sinto-me seco e sem raízes na vida. Por dentro de mim, como uma árvore única, estende-se a ramaria desta obra que tenho de escrever. Mas é uma coisa exterior a mim, uma fatalidade que não me absorve. Longos momentos vago a esmo, revendo a face dos seres que amei, países que habitei com tanta insistência, e que ficaram longe, separados de mim. Sinto-me como um exilado, e as terras que se aproximam, longe de me causar alegria, aparecem-me turvas, e não há mais segredo para mim neste contato, mas desconfiança e medo. ${ }^{16}$

Nas páginas 69 do texto datilografado e 218 do livro, as três primeiras palavras destacadas em negrito no fragmento acima converteram-se em "Sendo a mim mesmo uma inquietação, pergunto", o que, convenhamos, altera consideravelmente o sentido do que o autor pretendeu exprimir, ao passo que "a face dos seres" transformou-se em "as faces dos seres".

${ }^{16}$ Manuscritos do Diário, disponíveis para consulta no Arquivo Lúcio Cardoso da Fundação Casa de Rui Barbosa. Fragmento reproduzido com erros na p. 218 do Diário completo. 
Se a desatenção e a negligência explicam parte dos equívocos assinalados acima, somente elas não respondem por todos os outros erros do Diário completo, como a modificação de datas no fragmento sobre a Crônica da casa assassinada já deve ter podido indicar.

Em verdade, terminado o exame dos manuscritos do Diário que restaram no Arquivo Lúcio Cardoso, ${ }^{17}$ o leitor comprova, surpreso, que houve um propósito consciente de adulteração de datas na obra editada pela José Olympio e, mais, que ela não é, em absoluto, uma fonte fidedigna para o estudo da vida e da produção do romancista mineiro.

Todas as anotaçôes que se referem aos anos de 1952, 1953, 1954 e 1955, bem como algumas poucas que dizem respeito aos anos de 1956, 1957, 1958 e 1960, não foram efetivamente escritas por Lúcio Cardoso nos dias em que constam no livro. Nesse, 1951 dá origem a todo o ano de 1954, com exceção de três observações que fecham o mês de dezembro e não se encontram nos manuscritos, e a quase todo o ano de 1952. Trechos desse último ano, em compensação, foram deslocados para 1955, que contou também com fragmentos de 1949, 1950, 1954 e 1956. As únicas anotaçôes referentes ao ano de 1953, por sua vez, não foram incluídas na obra, que apresenta nesse ano fragmentos de outubro de 1954, novembro de 1955, dezembro de 1951 e de junho de 1950. Três apontamentos de 13 de novembro de 1955 foram reproduzidos com a data de 13 de janeiro de 1956 e um outro, de 17 de outubro de 1960; uma nota de 20 de outubro de 1956 foi publicada como sendo de 21 de setembro desse mesmo ano; há um trecho sem data, editado depois do dia 30 de setembro de 1957, que não integra os manuscritos e existem três fragmentos de 4 de setembro de 1958 que figuram, no entanto, como não-datados.

${ }^{17}$ Esses são compostos de uma caderneta, de cinco cadernos e de folhas avulsas correspondentes aos seguintes períodos:

Caderneta: de 7 de junho de 1950 a 3 de dezembro de 1950;

$1^{\circ}$ Caderno: de 20 dezembro de 1950 a 21 junho de 1951;

$2^{\circ}$ Caderno: de 17 agosto de 1951 a 5 setembro de 1952;

$3^{\circ}$ Caderno: de 6 setembro de 1952 a 9 dezembro de 1952;

$4^{\circ}$ Caderno: de 2 abril de 1957 a 9 julho de 1961;

$5^{\circ}$ Caderno: de 1 agosto de 1961 a 24 agosto de 1961;

Folhas avulsas: trechos datados de janeiro de 1953, outubro de 1954, novembro de 1955 e fevereiro, maio, setembro e outubro de 1956, além de alguns outros sem data. 
Surgem na obra, por fim, em meio às anotações desses anos, algumas outras que já haviam integrado o Diário I, publicado em 1960, o que demonstra que a sugestão dada por Octavio de Faria para que se estabelecesse uma comparação entre esse volume e o texto datilografado não foi capaz de assegurar a inexistência de repetições no Diário completo. O resultado é que trechos dos anos de 1949 a 1951 reaparecem, com datas diferentes, na parte relativa a 1952-1962, como pode ser confirmado pela leitura das páginas relacionadas abaixo:

$\begin{array}{rr}\text { Diário I } & \text { Diário II } \\ \text { página(s) } & \text { página(s) } \\ 22 & 272-273 \\ 42 & 208 \\ 89 & 184 \\ 90-91 & 204 \\ 93 & 184-185\end{array}$

Não há como precisar o que teria motivado a adulteração das datas dos fragmentos do Diário. Sabe-se que os escritos de Lúcio Cardoso não estavam organizados na época em que sofreu o derrame, fato que provocou até a inclusão involuntária de três poemas do amigo Emil de Castro no seu livro póstumo Poemas inéditos. Em carta a esse escritor, reproduzida por Ésio Macedo Ribeiro em sua dissertação de Mestrado, Maria Helena Cardoso desculpa-se pelo engano cometido no volume de poesia do irmão, fazendo referência à confusão em que os seus papéis se achavam e esclarecendo ainda que, no meio desses, havia muitos textos datilografados sem a devida identificação do autor:

Só agora posso explicar-lhe o que ocorreu: quando meu irmão voltou do hospital, veio diretamente para minha casa, sendo então alojado no quarto em que até então morava Walmir Ayala, que residia conosco. Este, por sua vez, transferiu-se provisoriamente, para o apartamento do Lúcio, vizinho ao meu, completamente mobiliado e com tudo que lhe pertencia. Por algum tempo a situação continuou como estava, até que, sabendo pelo médico que meu irmão não mais poderia viver só, encarreguei alguém de trazer para minha casa toda a papelada de Lúcio, que ele reclamava, guardada numa velha arca. $\mathrm{O}$ encarregado da incumbência, não me lembro mais quem, foi à residência do Walmir, ex do Lúcio, retirando todo o conteúdo da arca que trouxe dentro de um lençol amarrado como uma trouxa de roupa, 
me entregando. Posteriormente, a arca também foi removida vazia para meu apartamento. Imagine a misturada, a confusão da papelada, escritos, jornais, que assim permaneceram por muitos anos, pois era trabalho para uma pessoa que tivesse experiência do assunto. Anos passados quando Octavio [de] Faria começou a pedir pelos jornais qualquer poema do Lúcio a quem os tivesse, solicitou também que eu entregasse a ele tudo que estivesse em meu poder. Com muita dificuldade, catei tudo que estava datilografado e sem nome, retirando apenas alguns originais até mesmo de livros, escritos à mão, julgando que os à máquina pertencessem a Nonô. Entreguei-os a Octavio, que fez a escolha, os originais sendo posteriormente doados à Casa de Rui Barbosa que, a meu pedido, está fazendo uma busca rigorosa para ver se encontra alguma outra coisa que não seja de autoria dele. ${ }^{18}$

Se o relato de Maria Helena permite supor que originais do ficcionista teriam se extraviado antes de serem recebidos e catalogados no Arquivo da Fundação Casa de Rui Barbosa, ele é igualmente representativo das dificuldades e desafios enfrentados pelos organizadores dos livros de Lúcio editados postumamente. Nem por isso a complexidade da tarefa justifica a atitude condenável adotada para com os manuscritos do Diário, contudo. Os cadernos examinados no Arquivo não deixam dúvidas sobre a intenção de alterar as datas de parte dos apontamentos, eliminando por completo a hipótese de falha não-deliberada.

Ora, se houve deliberação, se houve intenção, se houve propósito determinando a modificação das datas, esses devem ter sido precedidos pela perda de uma parcela dos originais do Diário. Considerando que as incorreções e falhas do Diário completo praticamente desaparecem a partir de 1957 e, ainda, que não restaram cadernos relativos aos anos de 1953, 1954, 1955 e 1956, é possível presumir que o organizador do livro editado pela José Olympio teria decidido reordenar os fragmentos dos cadernos subsistentes de forma a "preencher as lacunas", por assim dizer. Para tanto, lançou mão do abundante material que o escritor havia produzido em anos anteriores, tendo se valido até de apontamentos anteriores a 17 de março de 1951, que ele havia decidido não incluir no primeiro volume do Diário.

${ }^{18}$ RIBEIRO, 2001, p. 174-175. 
O fato de as anotaçôes do terceiro caderno, que compreende o período de 6 de setembro a 9 de dezembro de 1952, permanecerem até hoje inéditas reforça, também, a idéia de uma certa negligência no manuseio e guarda dos originais de Lúcio Cardoso antes de sua doação ao Arquivo-Museu de Literatura Brasileira. Tal caderno provavelmente devia estar desaparecido na época da publicação do Diário completo e, tendo sido reencontrado depois disso, pôde ser encaminhado ao Arquivo, sem ter seu conteúdo incorporado à obra, obviamente. Percorreu, assim, uma trajetória inversa à do último caderno em que o romancista registrou suas anotaçōes, do qual só se tem notícia, hoje, por um texto de Marcos Konder Reis:

Meu caro Wilson: você me pediu, para este suplemento, que lhe mandasse alguma coisa sobre Lúcio Cardoso; de preferência, sobre o seu Diário. Acontece que já escrevi, mais de uma vez, sobre Lúcio, e já tentei dizer, desse Diário de fogo, o que me faz considerá-lo, não apenas o melhor, mas o mais importante dos diários publicados no Brasil. Hoje, não me sinto capaz de voltar ao tema, do jeito que, por ventura, você deseja. Vou, por isso, limitar-me a um caderno, um daqueles pequenos cadernos que tivemos um dia, como alunos do primário, em nossas mãos de meninos. Era um caderno de capa corde-rosa e pálida, onde Lúcio escreveu, de 29 de julho a 17 de outubro de 1962. Em abril, se não me engano, ele tivera uma pequena paralisia facial, que soara aos médicos como um grito de alerta, e a ele, como as batidas de seus próprios passos a caminho do derrame cerebral, que haveria de o derrubar no começo de dezembro. Em julho, liberado de um repouso mais completo, decidira, a conselho de médicos, familiares e amigos, passar um mês em Minas, a fim de restabelecerse. De volta, e já no fim de outubro, me pediu que lesse o que havia escrito naqueles dias de viagem, de vida no interior e de volta ao Rio, e que lhe desse minha opinião. Quando lhe disse, no final da leitura, entusiasmado, que, a meu ver, naquele caderno, ele havia escrito uma das coisas mais belas e mais fortes de toda a sua obra, me pareceu surpreso. No entanto, é possível que, no fundo, ele soubesse disso e me desse razão. Nem ele, nem eu, talvez, desconfiássemos de que o caderno, aquele seria o derradeiro: que, depois dele, a não ser trechos de novelas, que deixou por terminar, e trechos de $O$ viajante, que também nos legaria inacabado, só escreveu as respostas a uma 
entrevista publicada no Correio da Manhãa, de 20 de outubro de 1962, como seu derradeiro recado antes de emudecer. ${ }^{19}$

\section{À guisa de conclusão}

Tido até hoje como uma fonte fidedigna para o estudo da obra de Lúcio Cardoso, o Diário completo é citado em inúmeros ensaios, artigos, teses e livros sobre ele. A sua leitura deveria desvendar não apenas a interioridade do autor, por meio das anotaçôes de cunho mais pessoal, como também suas concepções sobre literatura, política, religião e os temas mais diversos. O volume poderia se constituir, ainda, em um documento valioso para o conhecimento de sua atividade literária, fornecendo elementos importantes sobretudo acerca da elaboração de seus romances e novelas.

Tal como foi organizado, no entanto, o livro se presta a uma série de falsas conclusões. Os exemplos de equívocos originados dos seus erros, disseminados nos estudos de vários pesquisadores, seriam muitos, caso se desejasse realizar, aqui, uma espécie de inventário. ${ }^{20}$ Sem pretender fazê-lo, enfatizo somente que a análise dos manuscritos do Diário se mostra imprescindível para o correto entendimento de como se deu o processo de composição dos romances e novelas iniciados por Lúcio a partir de 1951.

Através dela, comprova-se, por exemplo, que ele não teria trabalhado de forma alternada na redação da Crônica da casa assassinada e de O viajante. Como consequiência das alterações de datas no Diário completo, decorre obrigatoriamente a impressão de que o seu interesse por esses dois romances teria oscilado durante os anos, tendo, por isso, se dedicado ora à escrita de um, ora à de outro, o que não corresponde à verdade. Ao que tudo indica, o escritor abandonou o projeto de $O$ viajante no começo de 1952 e, meses mais tarde, lançou-se à execução da Crônica, de cuja formulação não desistiu enquanto não a viu terminada.

Um dado como esse demonstra que urge preparar uma nova edição do Diário completo, que não apenas retifique os seus muitos erros, mas que ainda acrescente os vários apontamentos que continuam inéditos. Lúcio, sua obra, seus leitores e pesquisadores, todos nós, enfim, ganharíamos muito com isso.

${ }^{19}$ REIS, 20 out. 1973.

${ }^{20}$ Equívocos dos quais eu própria não escapei em alguns de meus textos, convém assinalar. 


\section{Referências Bibliográficas}

AMADO, Jorge. Página de diário sobre um Diário. Leitura, Rio de Janeiro, n. 42, p. 10, dez. 1960.

AYALA, Walmir. Diário: Lúcio Cardoso - a véspera do livro. Jornal do Brasil. Suplemento dominical, Rio de Janeiro, 10 set. 1960.

BANDEIRA, Manuel. Lúcio Cardoso. Folha de S. Paulo, São Paulo, 3 dez. 1960. (Publicado, também, na p. 768 da edição crítica da Crônica da casa assassinada e em Andorinha, andorinha. Rio de Janeiro: José Olympio, 1966, p. 231-232, sob o título "Diário de romancista".)

CARDOSO, Lúcio. Diário I. Rio de Janeiro: Elos, [1960].

. Diário completo. Rio de Janeiro : José Olympio/INL, 1970.

. Lúcio Cardoso (patético): "Ergo meu livro como um punhal contra Minas".

Jornal do Brasil. Caderno B, Rio de Janeiro, 25 nov. 1960. Entrevista concedida a [Fausto Cunha]. (Publicada equivocadamente como inédita e sem reproduzir as questões e os comentários feitos pelo entrevistador em Ficção, Rio de Janeiro, n. 2, p. 71-72, fev. 1976.)

CARELLI, Mario. Corcel de fogo: vida e obra de Lúcio Cardoso (1912-1968). Rio de Janeiro : Guanabara, 1988.

CONDÉ, José. Lúcio Cardoso responde e ataca. Correio da Manhãa, Rio de Janeiro, 30 abr. 1959.

FUNDAÇÃO CASA DE RUI BARBOSA. Inventário do arquivo Lúcio Cardoso. Org. de Rosângela Florido Rangel e Eliane Vasconcellos Leitão. Rio de Janeiro, 1989. 120 p. (CLB, 4.)

MEIRA, Mauritônio. Diários íntimos de Lúcio Cardoso serão publicados finalmente: pela Simões. Jornal do Brasil. Caderno B, Rio de Janeiro, 31 maio 1960.

MONTENEGRO, Olívio. Um romance imoral. Diário de Pernambuco, Recife, 26 abr. 1959. (Republicado em Diário Carioca, Rio de Janeiro, 17 maio 1959.)

REIS, Marcos Konder. Carta a Lúcio Cardoso. Minas Gerais - suplemento literário, Belo Horizonte, 30 nov. 1968.

. Lembrança de um caderno. Tribuna da Imprensa. Tribuna Literária, Rio

de Janeiro, 20 out. 1973. 
RIBEIRO, Ésio Macedo. O riso escuro ou o pavão de luto: um percurso pela poesia de Lúcio Cardoso. São Paulo, 2001. 285 p. Dissertação (Mestrado em Letras Teoria Literária e Literatura Comparada), Faculdade de Filosofia, Letras e Ciências Humanas, Universidade de São Paulo.

\section{Outros textos citados, consultados no Arquivo Lúcio Cardoso na Fundação Casa de Rui Barbosa}

CARTA de Octavio de Faria a Lúcio Cardoso. Teresópolis, 13 abr. 1967. 4 fls.

CONTRATO entre a Livraria José Olympio Editora S.A. e Maria Helena Cardoso para a publicação do Diário completo de LC. Rio de Janeiro, s.d. 3 fls.

MANUSCRITOS e datiloscritos do Diário.

\section{Resenhas e textos sobre a Crônica da casa assassinada (em ordem cronológica)}

OLINTO, Antônio. Crônica da casa assassinada. O Globo, Rio de Janeiro, 4 abr. 1959. (Republicado em $A$ verdade da ficção. Rio de Janeiro: Companhia Brasileira de Artes Gráficas, 1966, p. 149-152.)

PIRES, Herculano. Crônica da casa assassinada. Diário da Noite, São Paulo, 25 abr. 1959.

ADONIAS FILHO. Crônica da casa assassinada. Jornal do Commercio, Rio de Janeiro, 26 abr. 1959.

MONTENEGRO, Olívio. Um romance imoral. Diário de Pernambuco, Recife, 26 abr. 1959. (Republicado em Diário Carioca, Rio de Janeiro, 17 maio 1959.)

CONDÉ, José. Lúcio Cardoso responde e ataca. Correio da Manhā, Rio de Janeiro, 30 abr. 1959.

CRUZ, Luiz Santa. Romance demonológico. Leitura, Rio de Janeiro, n. 22, abr. 1959.

ATHAYDE, José Constâncio Austregésilo de. Crônica da casa assassinada. Jornal do Commercio, Rio de Janeiro, 29 maio 1959.

ROMANCE imoral. Jornal do Brasil. Suplemento Dominical, Rio de Janeiro, 30 maio 1959.

HECKER FILHO, Paulo. Uma proeza bem cumprida. O Estado de S. Paulo. Suplemento Literário, São Paulo, 30 maio 1959. 
LINHARES, Temístocles. Outro Lúcio Cardoso. O Estado de S. Paulo. Suplemento Literário, São Paulo, 6 jun. 1959. (Republicado em Diário de Notícias. Letras e Artes, Rio de Janeiro, 21 jun. 1959.)

AYALA, Walmir. Crônica da casa assassinada: um romance imoral? Correio da Manhä, Rio de Janeiro, 6 jun. 1959.

OLIVEIRA, José Carlos. Um romancista de Minas. Jornal do Brasil. Suplemento Dominical, Rio de Janeiro, 13 jun. 1959.

AYALA, Walmir. Crônica da casa assassinada: um romance imoral? (II). Correio da Manhã, Rio de Janeiro, 20 jun. 1959.

OLIVEIRA, José Carlos. O labirinto. Jornal do Brasil. Suplemento Dominical, Rio de Janeiro, 20 jun. 1959.

OLIVEIRA, José Carlos. Mentira e verdade. Jornal do Brasil. Suplemento Dominical, Rio de Janeiro, 27 jun. 1959.

LEITE, José Roberto Teixeira. O novo livro de Lúcio Cardoso. Jornal de Letras. Rio de Janeiro, ano XI, n. 119, p. 13, jun. 1959. (Republicado em Anuário da Literatura Brasileira, Rio de Janeiro, ano I, n. 1, 1960.)

OLIVEIRA, José Carlos. Mentira e verdade (conclusão). Jornal do Brasil. Suplemento Dominical, Rio de Janeiro, 4 jul. 1959.

LITRENTO, Oliveiros. O abismo da carne. Jornal de Letras, Rio de Janeiro, ano XI, n. 120, jul./ago. 1959.

MARTINS, Wilson. Um romance brasileiro. O Estado de S. Paulo. Suplemento Literário, São Paulo, 1 ago. 1959.

GERSEN, Bernard. Tempo e técnica romanesca. Diário de Notícias. Letras e Artes, Rio de Janeiro, 2 ago. 1959. (Republicado com cortes em O Estado de S. Paulo. Suplemento Literário, São Paulo, 29 out. 1960.)

GOES, Carlos Augusto de. Romance epistolar. Diário Carioca, Rio de Janeiro, 2 ago. 1959.

SANTOS, Vitto. A casa assassinada. Diário de Notícias. Letras e Artes, Rio de Janeiro, 16 ago. 1959.

LOUZADA FILHO. O tempo assassino. O Estado de S. Paulo. Suplemento Literário, São Paulo, 5 set. 1959.

AYALA, Walmir. Crônica da casa assassinada. Jornal do Brasil. Suplemento Dominical, Rio de Janeiro, 12 set. 1959. 


\section{Resumo}

Autor de vários romances e novelas, dos quais o mais conhecido é a Crônica da casa assassinada, Lúcio Cardoso manteve durante anos um diário íntimo, cujo primeiro volume lançou no fim de 1960. Dois anos após a morte do escritor, em 1970, a José Olympio reuniu as anotações já editadas a outras inéditas, publicando-as sob o título de Diário completo. Adotado desde então como fonte fidedigna para o estudo da vida e da produção de Lúcio Cardoso, o livro se ressente, porém, de graves falhas. $\mathrm{O}$ exame de parte de seus originais, depositados no Arquivo-Museu de Literatura Brasileira da Fundação Casa de Rui Barbosa, demonstra que urge preparar uma nova edição da obra, que não apenas retifique seus muitos erros, mas que também acrescente os fragmentos do Diário que ainda seguem inéditos.

\section{Abstract}

Writer of novels and short novels, the most famous being Crônica da casa assassinada, Lúcio Cardoso for years mantained a diary, the first volume of which was published in 1960. In 1970, two years after his death, his publishing house, José Olympio, collected what was supposed to be the Diário completo. The book, however, suffers from grave defects. Examination of the original manuscripts at the Arquivo-Museu de Literatura Brasileira of Fundação Casa de Rui Barbosa reveals the necessity of a new edition, not only to correct the various errors of the 1970 edition, but to add pieces that were left out at that time. Author of several novels and novels, of which the most known thing is the Chronicle of the murdered house, Pike Cardoso maintained during years an intimate diary, which first volume launched in the end of 1960 . Two years after the death of the writer, in 1970, to José Olympio it joined the annotations already published to unpublished others, publishing them under the title of complete Diary. Adopted from that time like trustworthy fountain for the study of the life and of the production of Pike Cardoso, the book resents, however, serious faults. The examination of part of his originals, deposited in the Archive-museum of Brazilian Literature of the Foundation House of Collapse Barbosa, demonstrate what is urgent to prepare a new publication of the work, what you do not punish rectifies his many mistakes, but what it also adds the fragments of the Diary that are still still unpublished. 


\section{ANEXOS}

Originais manuscritos do Diário de Lúcio Cardoso e páginas do Diário completo.

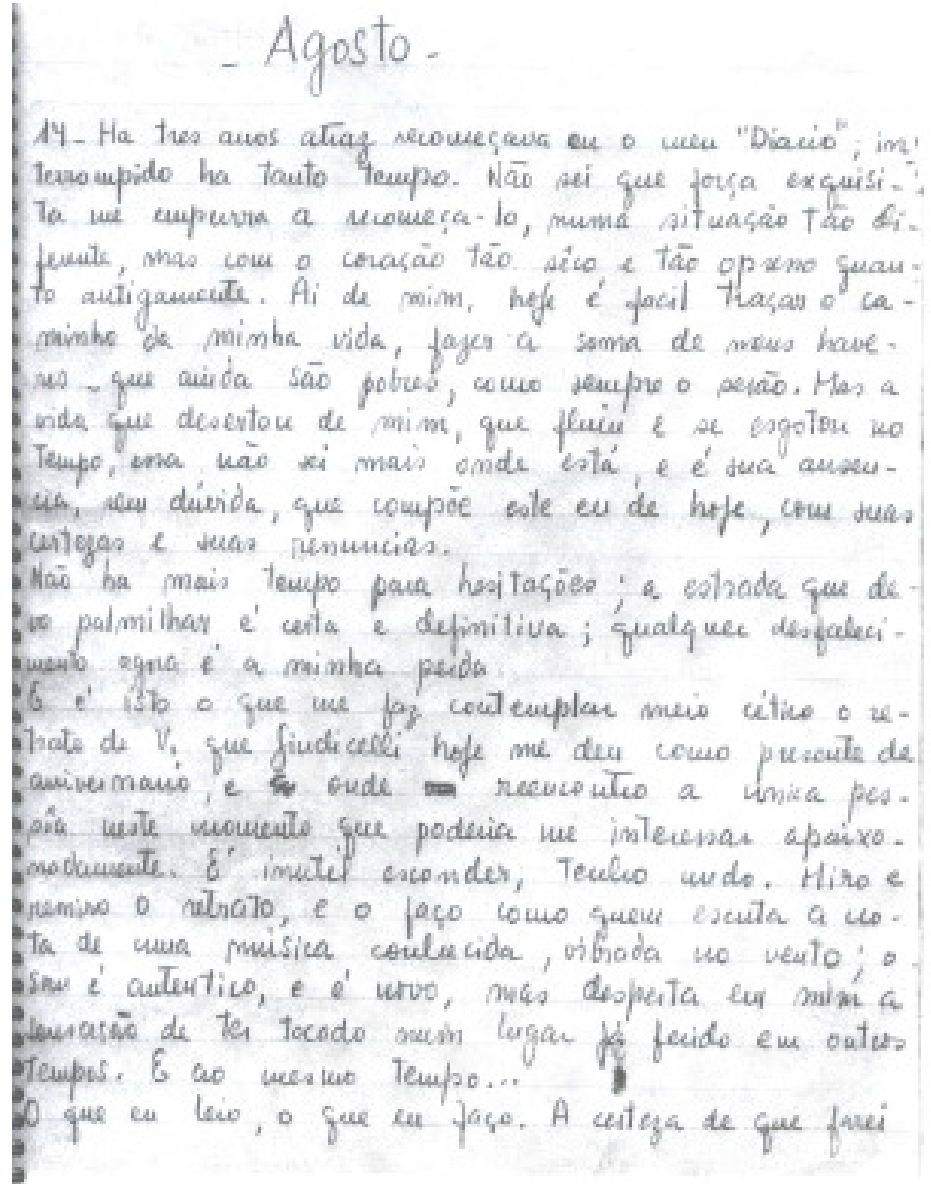

Com a substituição da palavra "anos" por "meses" e a data trocada para 14 de agosto de 1955, esse fragmento, que é de 14 de agosto de 1952, foi incluído nas páginas 204-205 do Diário completo. 


\section{3}

\section{Janeiro.}

27. Escrevo, excuvo sew parar a "Cromica da Casa Assai. simoda". Ha muito naio conhrecia una tâo bôa disposi sio, new sorever we parcia uma tarefa mais apadarel. Av

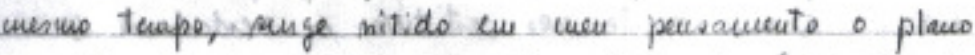
de outio cowarce: "As chaver do abiswe", Estaria anims comprosta a thilesia (o $1^{\prime}:$ "Retrete do vigjasite") cove que poube ha muite, e va qual o tempe, cone unia música en durdina, tem täe decisiva impotancia.

Continuio os plawos para a fageuda. O dia tarda en que la we uya irstalado, e clugs $a$ sonhas a' woite cour siluasóes angustiosas (o qui i comum) mas tudo velative aos nens planes de campe, Bibliotéca ace. mulloda. coder nos, condusāo - quaudo dugara' a hara da liberdede?

s/d. Todos os mens livos un os fiz à margenn de minhas paixöes; quaudo snimbas paixöes éque deveriam viver a' praigem des mons lives

Felicidade de poder constatar isto a tempo.

Totalmente inéditos, esses apontamentos constam de uma das folhas avulsas que subsistiram do Diário do autor. O primeiro deles contém a primeira menção explícita à Crônica da casa assassinada nos originais existentes no Arquivo da Fundação Casa de Rui Barbosa. 

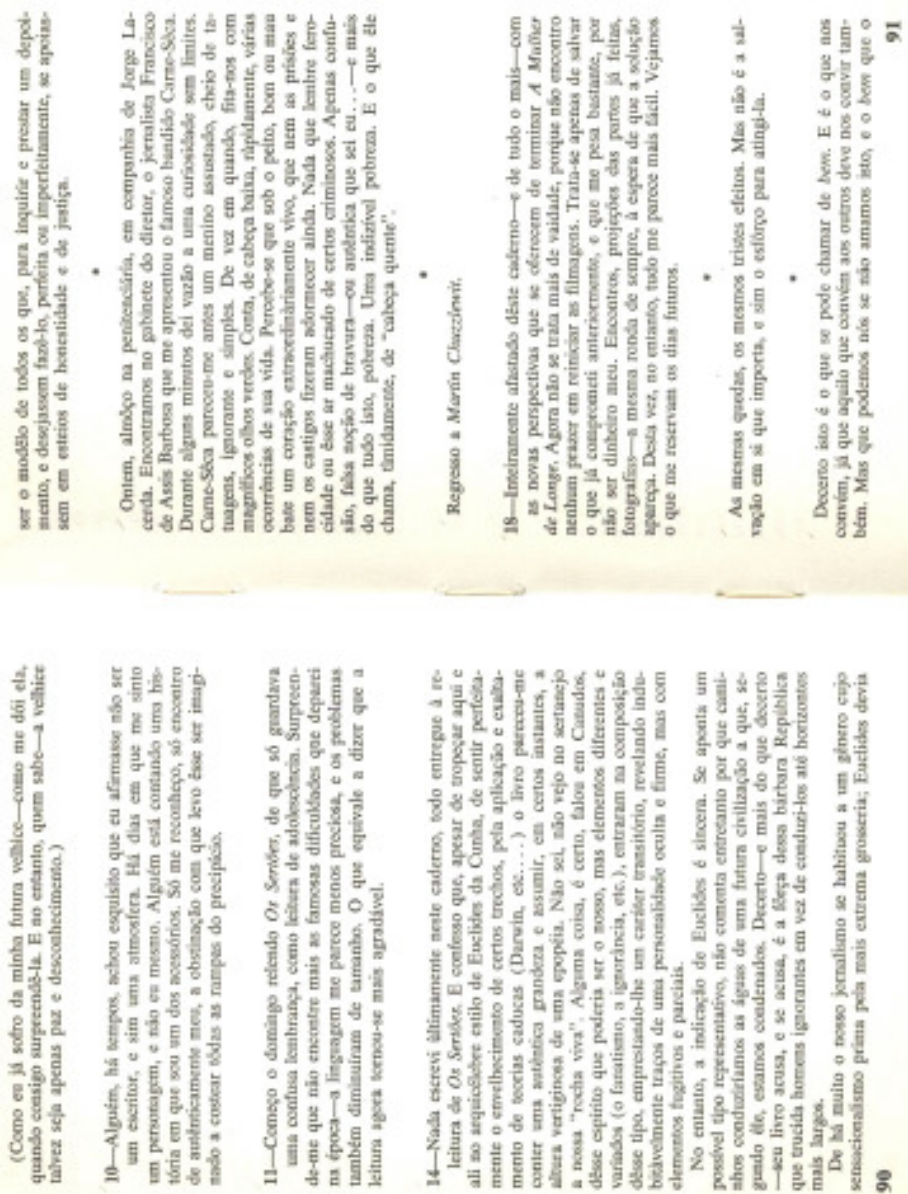

Os trechos relativos aos dias 10 e 18 são de junho de 1950 e integram, como os demais, a primeira parte do Diário completo. Na página 204 do livro, reproduzida adiante, figuram com a data de 10 e 18 de junho de 1955 . 

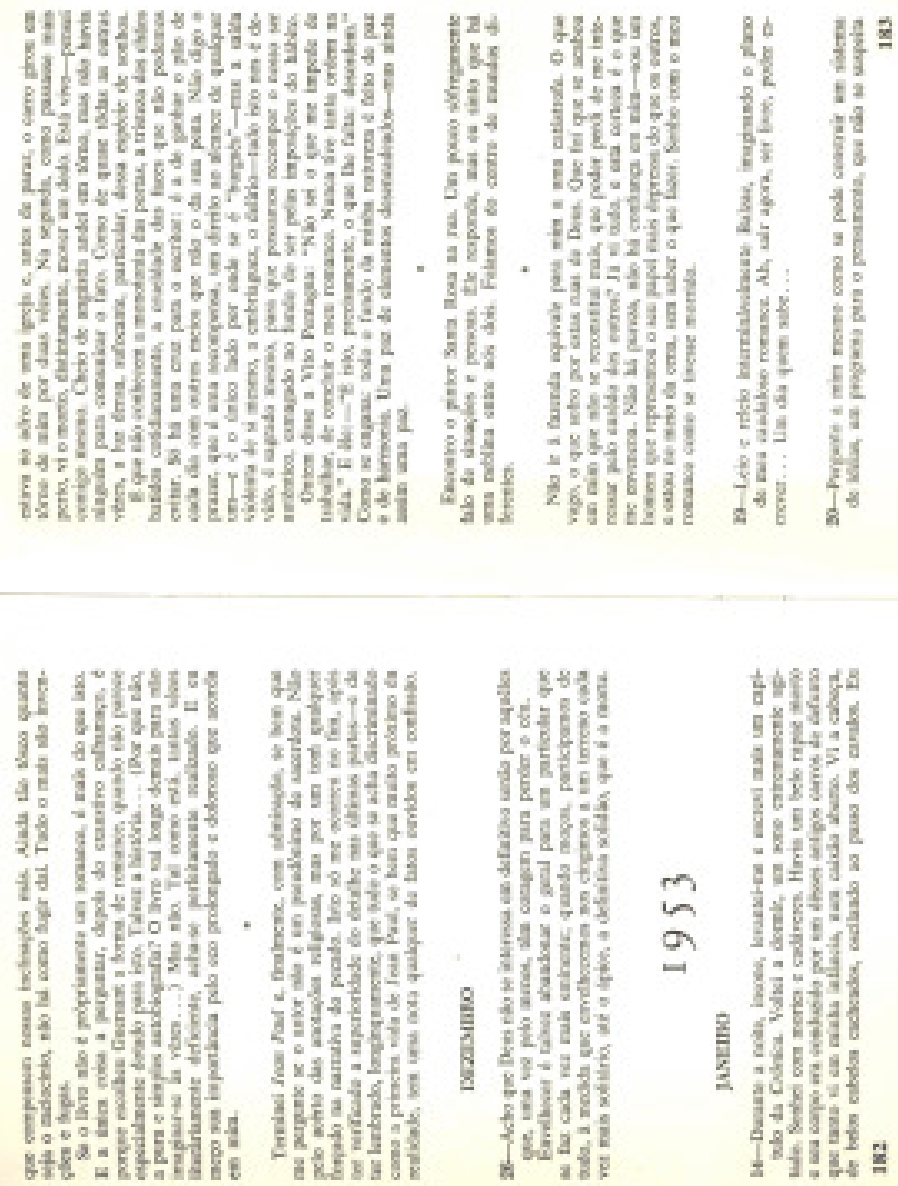

Essas páginas apresentam aquela que se julgava ser a primeira referência explícita à Crônica da casa assassinada no Diário do escritor. O trecho em questão é composto de apontamentos de dias diferentes: o primeiro parágrafo é de 14 de novembro de 1955, o segundo integra uma anotação maior, do dia 18 de outubro de 1954, e o terceiro também é desse mesmo dia, embora se constitua em um apontamento autônomo. Os demais fragmentos editados nessas páginas também tiveram suas datas alteradas. 

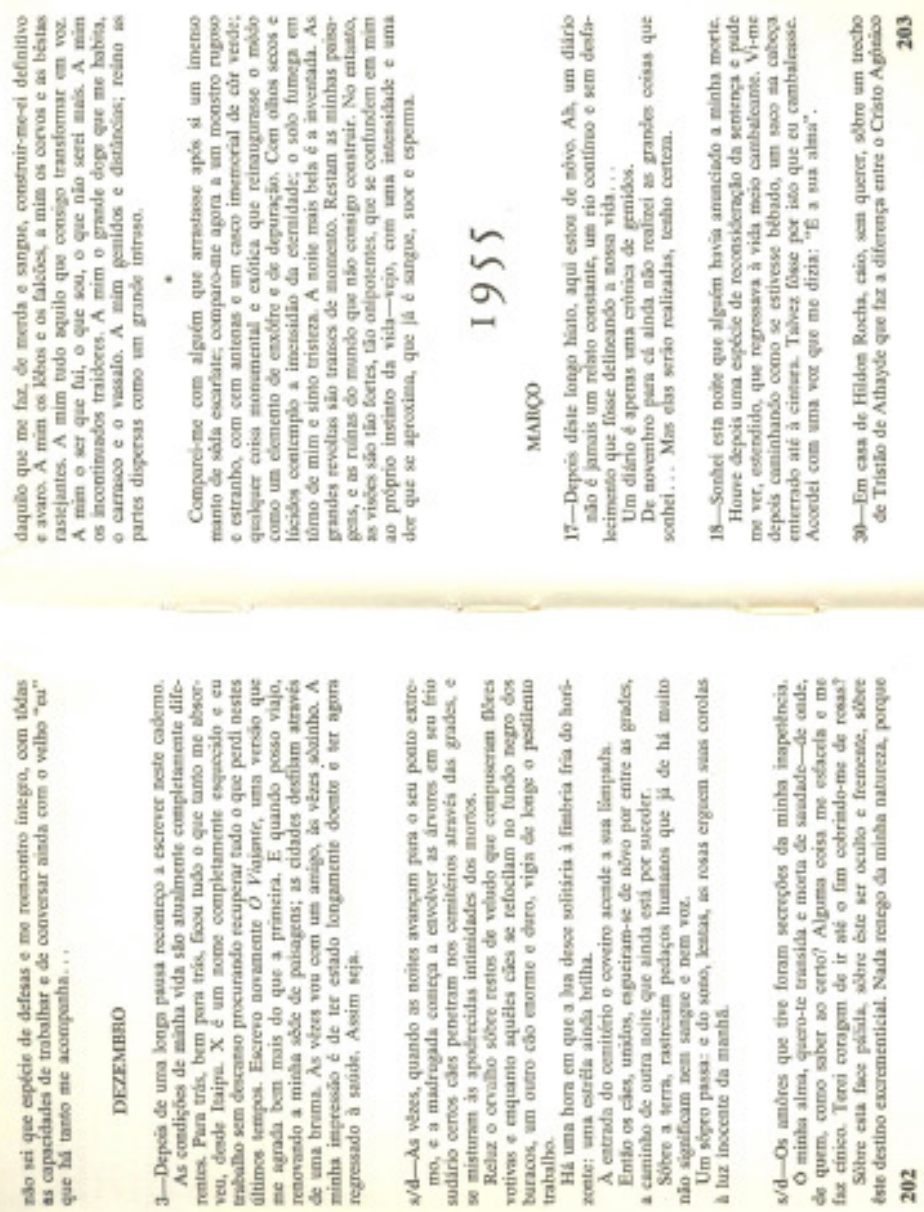

O trecho impresso com a data de 3 de dezembro de 1954 é de 3 de dezembro de 1951; os três fragmentos subseqüentes, sem data, não integram o segundo caderno de manuscritos do Diário, que compreende o período de 17 de agosto de 1951 a 5 de setembro de 1952 (veja nota 17 nesse ensaio); as três anotações seguintes são de 17, 18 e 30 de março de 1952 . 

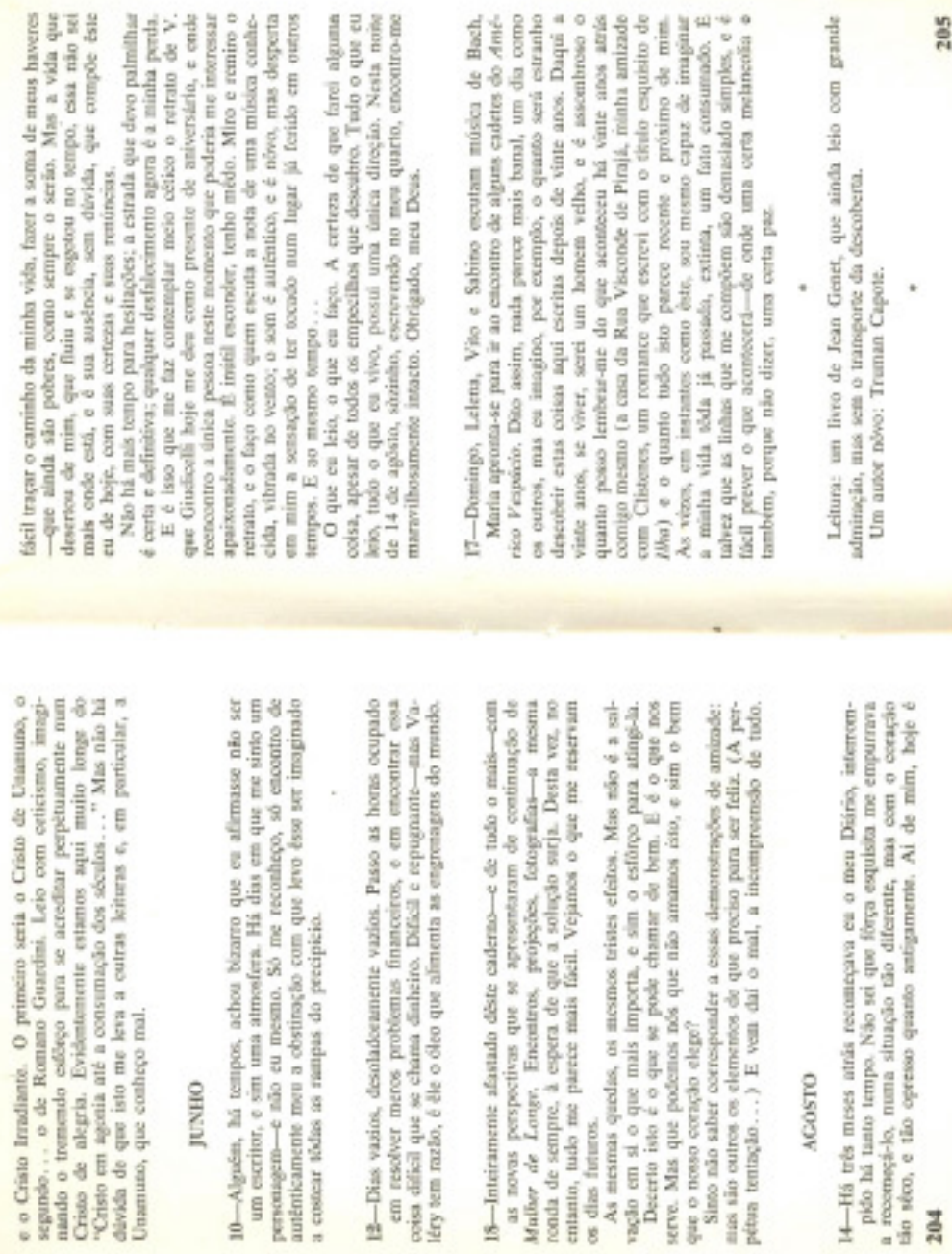

Páginas do Diário completo com fragmentos já apresentados nas p. 90-91 e com o apontamento de 14 de agosto de 1952, já reproduzido nesses Anexos. 